\title{
Increased Neuronal Differentiation of Neural Progenitor Cells Derived from Phosphovimentin-Deficient Mice
}

\author{
Meng Chen ${ }^{1}$ - Till B. Puschmann ${ }^{1}$ • Pavel Marasek ${ }^{1}$ - Masaki Inagaki ${ }^{2}$. \\ Marcela Pekna $^{3,4,5}$ • Ulrika Wilhelmsson ${ }^{1} \cdot$ Milos Pekny $^{1,4,5}$
}

Received: 8 April 2017 / Accepted: 27 August 2017 / Published online: 27 September 2017

(C) The Author(s) 2017. This article is an open access publication

\begin{abstract}
Vimentin is an intermediate filament (also known as nanofilament) protein expressed in several cell types of the central nervous system, including astrocytes and neural stem/progenitor cells. Mutation of the vimentin serine sites that are phosphorylated during mitosis $\left(V I M^{S A / S A}\right)$ leads to cytokinetic failures in fibroblasts and lens epithelial cells, resulting in chromosomal instability and increased expression of cell senescence markers. In this study, we investigated morphology, proliferative capacity, and motility of VIM ${ }^{S A / S A}$ astrocytes, and their effect on the differentiation of neural stem/progenitor cells. VIM ${ }^{S A / S A}$ astrocytes expressed less vimentin and more GFAP but showed a welldeveloped intermediate filament network, exhibited normal cell morphology, proliferation, and motility in an in vitro wound closing assay. Interestingly, we found a two- to fourfold increased neuronal differentiation of VIM ${ }^{S A / S A}$ neurosphere cells, both in a standard 2D and in Bioactive3D cell culture systems, and determined that this effect was neurosphere cell autonomous and not
\end{abstract}

Milos Pekny

milos.pekny@neuro.gu.se

1 Laboratory of Astrocyte Biology and CNS Regeneration, Center for Brain Repair and Rehabilitation, Department of Clinical

Neuroscience, Institute of Neuroscience and Physiology, Sahlgrenska Academy at the University of Gothenburg, Box 440, 40530 Gothenburg, Sweden

2 Department of Physiology, Mie University Graduate School of Medicine, Mie, Japan

3 Laboratory of Regenerative Neuroimmunology, Center for Brain Repair and Rehabilitation, Department of Clinical Neuroscience, Institute of Neuroscience and Physiology, Sahlgrenska Academy at the University of Gothenburg, Gothenburg, Sweden

4 Florey Institute of Neuroscience and Mental Health, Parkville, VIC, Australia

5 University of Newcastle, Newcastle, NSW, Australia dependent on cocultured astrocytes. Using BrdU in vivo labeling to assess neural stem/progenitor cell proliferation and differentiation in the hippocampus of adult mice, one of the two major adult neurogenic regions, we found a modest increase (by $8 \%$ ) in the fraction of newly born and surviving neurons. Thus, mutation of the serine sites phosphorylated in vimentin during mitosis alters intermediate filament protein expression but has no effect on astrocyte morphology or proliferation, and leads to increased neuronal differentiation of neural progenitor cells.

Keywords Intermediate filaments · Nanofilaments · Vimentin · GFAP · Astrocytes · Neural stem/progenitor cells · Bioactive3D culture system

\section{Introduction}

The intermediate filament system (known also as nanofilament system) of astrocytes is a dynamic integrator of cellular functions under physiological conditions and plays an important role in times of cellular stress as well as in the subsequent regenerative processes [1-6]. Whereas the upregulation of intermediate filament proteins in astrocytes is important for the confinement of the lesion area in brain injury, ischemic stroke, retinal ischemia, or spinal cord injury, it inhibits some of the regenerative processes later on $[4,5]$. We and others previously demonstrated that mice carrying null mutations in genes encoding glial fibrillary acidic protein (GFAP) and vimentin $\left(G F A P^{-/} \mathrm{Vim}^{-/-}\right.$mice $)$have astrocytes devoid of astrocyte intermediate filaments $[7,8]$ and exhibit better posttraumatic regeneration of neuronal synapses and axons $[9,10]$, improved functional recovery after spinal cord injury [11], reduced photoreceptor degeneration in the retinal detachment model [12], and reduced pathological neovascularization in oxygen-induced retinopathy [13]. We also demonstrated that in GFAP ${ }^{-/} \mathrm{Vim}^{-/-}$mice, retinal grafts can better integrate [14], 
differentiation of transplanted neural stem cells into neurons and astrocytes is enhanced [15], and hippocampal neurogenesis is increased in naïve mice [16], after neonatal hypoxic-ischemic injury [17], or after neurotrauma [16]. The astrocyte intermediate filament system is important for the ability of astrocytes to cope with conditions associated with cellular stress, such as that induced by ischemia reperfusion [18-20]. We have shown that the astrocyte intermediate filament system regulates Notch signaling from astrocytes to neural stem/progenitor cells, a mechanism that inhibits differentiation of neural progenitors into neurons, astrocytes, or oligodendrocytes in the adult brain $[16,21]$. Thus, in a variety of injury models, the benefits of reactive gliosis in the acute stage of central nervous system injury is balanced against restricted regenerative potential at the later stage, and hence modulation of reactive gliosis targeting the intermediate filament system might lead to enhanced recovery after central nervous system injury.

The highly dynamic assembly and disassembly of intermediate filaments is essential for the function of the intermediate filament system [22-24]. Intermediate filament phosphorylation is a key regulator of intermediate filament dynamics and is crucial for the organization of the intermediate filament network and the subcellular distribution of intermediate filament proteins [25, 26]. The intermediate filament disassembly, regulated by phosphorylation of serine/threonine residues in the amino-terminal head domain of intermediate filament proteins [24, 27], was reported to be essential for the efficient separation of the two daughter cells during mitosis [28-32]. In various cell types, including astrocytes, some of the key vimentin phosphorylation sites and their respective protein kinases have been identified [28-30, 33-41]. Phosphovimentin-deficient mice (VIM ${ }^{S A / S A}$ mice), i.e., mice expressing vimentin in which all the serine sites that are phosphorylated during mitosis were substituted by alanine residues, show cytokinetic failures in fibroblasts and lens epithelial cells resulting in aneuploidy, chromosomal instability, and increased expression of cell senescence markers [42]. VIM ${ }^{S A / S A}$ mice exhibit a phenotype of pre-mature aging, including cataract development in lens, delayed skin wound healing, and subcutaneous fat loss in old age $[42,43]$. Here, we investigated whether the vimentin phosphorylation deficit in $V I M^{S A / S A}$ mice alters astrocyte morphology, proliferative capacity, and motility, and whether the phosphovimentin-deficient astrocyte niche affects neuronal differentiation of neural progenitor cells in vitro and neurogenesis in vivo.

\section{Experimental Procedures}

\section{Animals}

In $\operatorname{Vim}^{S A / S A}$ mice, the serine residues in the vimentin head domain identified as phosphorylation sites during mitosis (Ser-6, Ser-24, Ser-38, Ser-46, Ser-55, Ser-64, Ser-65, Ser-
71, Ser-72, Ser-82, and Ser-86) were replaced by alanine [42]. The $\operatorname{Vim}^{S A}$ mutation was on $\mathrm{C} 57 \mathrm{Bl} / 6$ genetic background, the colony was maintained as heterozygotes, and the experimental groups were genotyped by PCR. All mice were housed in standard cages in a barrier animal facility and had free access to food and water. All the experiments were conducted according to protocols approved by the Ethics Committee of the University of Gothenburg (Dnr. 247-2014).

\section{Astrocyte Cultures}

Postnatal day 0.5-2.5 mouse cortical tissue was dissected in cold Dulbecco's phosphate-buffered saline (DPBS) (Thermo Fisher Scientific), cut into small pieces, incubated in $0.05 \%$ trypsin-ethylenediaminetetraacetic acid (EDTA) solution (Thermo Fisher Scientific) at $37^{\circ} \mathrm{C}$ for $10 \mathrm{~min}$, and mechanically dissociated into a single cell suspension. Single cell suspension isolated from each mouse brain were seeded in a poly-D-lysine-coated (10 $\mu \mathrm{g} / \mathrm{mL}$; Sigma-Aldrich) T75 culture flask (Sarstedt) in Dulbecco's minimal essential medium (DMEM) (Thermo Fisher Scientific) supplemented with 1\% Pen/Strep (Thermo Fisher Scientific), 1\% L-glutamine (Thermo Fisher Scientific), and 10\% heat-inactivated fetal calf serum (FCS; HyClone/Thermo Fisher Scientific). The contamination of non-astrocyte cells in these cultures was minimalized as previously described [19, 44]. For astrocyte proliferation assay, 10,500 cells $/ \mathrm{cm}^{2}$ were seeded in poly-Dlysine-coated 6-well culture plates. For scratch wound live imaging recording, 12,500 cells $/ \mathrm{cm}^{2}$ were seeded in poly-Dlysine-coated 12-well culture plates. For intermediate filament bundle imaging and cell size/polynucleation assessment, primary astrocytes were detached (trypsinized) by incubating with $0.25 \%$ trypsin-EDTA solution (Thermo Fisher Scientific) at $37{ }^{\circ} \mathrm{C}$ for $10 \mathrm{~min}$ and reseeded on poly-D-lysine-coated coverslips placed in 24-well culture plates (TPP), at a density of 30,000 cells $/ \mathrm{cm}^{2}$.

\section{Astrocyte Proliferation Assay and Scratch Wound Healing Assay}

For astrocyte proliferation assay, primary astrocytes cultured in 6-well culture plates were collected on 4, 8, 12, 16, 20, and 24 days in vitro (DIV), trypsinized, and resuspended in astrocyte medium for cell counting. The cell number per milliliter medium was determined by a Countess automated cell counter (Thermo Fisher Scientific). For astrocyte wound healing assay, an approximate $800 \mu \mathrm{m}$ wide wound was made by scratching with a $1-\mathrm{mL}$ pipette tip on 14-day-old primary astrocytes cultured in a 12 -well culture plate. The plate was then placed on a Leica DMI 6000B microscope connected to an incubator chamber supplied with humid atmosphere of $37{ }^{\circ} \mathrm{C}$ and $5 \% \mathrm{CO}_{2}$. Images were taken every $12 \mathrm{~h}$ automatically for a total of $132 \mathrm{~h}$. 


\section{Neurosphere Cultures}

Postnatal day 2.5-3.5 mouse forebrain was dissected in cold DPBS (Thermo Fisher Scientific), cut into small pieces, incubated in TrypLE solution (Thermo Fisher Scientific) at $37{ }^{\circ} \mathrm{C}$ for $10 \mathrm{~min}$, and mechanically dissociated into a single cell suspension. The dissociated cells were plated in neurosphere medium composed of Neurobasal medium (Thermo Fisher Scientific), supplemented with $1 \%$ Pen/Strep (Thermo Fisher Scientific), 1\% L-glutamine (Thermo Fisher Scientific), 2\% B27 (Thermo Fisher Scientific), $20 \mathrm{ng} / \mathrm{mL}$ bFGF (Thermo Fisher Scientific), $20 \mathrm{ng} / \mathrm{mL}$ EGF (Thermo Fisher Scientific), and $1 \mathrm{U} / \mathrm{mL}$ Heparin (Sigma-Aldrich). Dissociated brain cells were plated at a density of 8000 cells $/ \mathrm{cm}^{2}$ in T25 cell suspension culture flasks (Sarstedt; for neurosphere expansion) or $12,500 \mathrm{cells} / \mathrm{cm}^{2}$ in 12-well suspension culture plates (Greiner Bio One; for neurosphere quantification) to form neurospheres. Neurospheres were passaged on 7 DIV by dissociation of neurosphere cells with TrypLE solution (Thermo Fisher Scientific) into a single cell suspension, which was then replated. To quantify secondary and quaternary neurospheres, primary and tertiary neurospheres, respectively, were dissociated and plated at a density of $5000 \mathrm{cells} / \mathrm{cm}^{2}$ in 48 -well cell suspension culture plates (Greiner Bio One).

\section{Neurosphere Differentiation}

On 7 DIV, primary neurospheres were collected, dissociated by TrypLE, and allowed to differentiate in differentiation medium on poly-L-ornithine- $(0.01 \mathrm{mg} / \mathrm{mL}$; Sigma-Aldrich) and laminin-coated (5 $\mu \mathrm{g} / \mathrm{mL}$; Thermo Fisher Scientific) 24-well culture plates (TPP) or on poly-L-ornithine- and laminincoated Bioactive3D nanofiber scaffolds (3Dtro) placed in 24-well culture plates. The differentiation medium was composed of Neurobasal medium (Thermo Fisher Scientific) supplemented with 1\% Pen/Strep (Thermo Fisher Scientific), $1 \%$ L-glutamine (Thermo Fisher Scientific), 2\% B27 (Thermo Fisher Scientific), and $1 \%$ heat-inactivated fetal calf serum (HyClone/Thermo Fisher Scientific). Differentiated cells were cultured for 5 days before examination. For immunocytochemical analysis, neurospheres were allowed to adhere on a poly-D-lysine-coated 24-well culture plate, and cultured for $24 \mathrm{~h}$ before examination.

\section{Astrocyte-Neurosphere Cocultures}

At confluency (6-7 DIV), primary astrocytes were trypsinized and plated in poly-L-ornithine- and laminin-coated 24-well culture plates or Bioactive3D nanofiber scaffolds placed in 24well culture plates. Twenty-four hours later, the culture medium was changed to neurosphere differentiation medium. When confluent (2-3 days), dissociated primary neurosphere cells were plated on astrocytes. To label the neurosphere cells,
$0.5 \mu \mathrm{M}$ 5-bromo-2'-deoxyuridine (BrdU) was added into the neurosphere culture $48 \mathrm{~h}$ before dissociation. The neurosphere cells were allowed to differentiate in the coculture for 5 days before examination.

\section{Immunocytochemistry}

Cells were washed in DPBS and fixed in 4\% paraformaldehyde (PFA; Sigma-Aldrich), followed by blocking unspecific binding sites using blocking buffer. The blocking buffer consisted of DPBS supplemented with $2 \%$ donkey serum (Jackson Immunoresearch), 2\% goat serum (Jackson Immunoresearch), and $0.1 \%$ Triton-X 100 (Sigma-Aldrich). The cells were then incubated with primary antibodies at $4{ }^{\circ} \mathrm{C}$ overnight. For detection of BrdU, cells were first treated with $2 \mathrm{M} \mathrm{HCl}$ at $37^{\circ} \mathrm{C}$ for $10 \mathrm{~min}$. Proteins of interest were detected using the following primary antibodies: rabbit antinestin (1:1500; Covance), rabbit anti-GFAP (1:1500; Dako), chicken anti-vimentin (1:1500; Biolegend), mouse anti- $\beta$ IIItubulin (1:1500; Covance), mouse anti-MAP2 (1:1500; Sigma-Aldrich), and rat anti-BrdU (1:200; Serotec). Fluorophore-conjugated secondary antibodies were used at a dilution of 1:2000 and incubated with the cells for $1.5 \mathrm{~h}$ at room temperature (RT). Secondary antibodies used were as follows (all from Thermo Fisher Scientific): Alexa 594conjugated goat anti-mouse, Alexa 488-conjugated donkey anti-mouse, Alexa 555-conjugated donkey anti-rabbit, Alexa 488-conjugated donkey anti-rabbit, Alexa 488-conjugated donkey anti-rat, Alexa 647-conjugated goat anti-chicken, and Alexa 647-conjugated goat anti-rat. Cell nuclei were visualized by DAPI (Sigma-Aldrich). Fluorescence-labeled cell cultures were imaged and analyzed using either a Leica DMI 6000B microscope (Leica) or a LSM 700 confocal microscope (Zeiss). Only $\beta$ III-tubulin ${ }^{\text {pos }}$ cells negative for GFAP were regarded as neurons and only GFAP ${ }^{\text {pos }}$ cells negative for $\beta$ III-tubulin were regarded as astrocytes. The images were analyzed by Image J software.

For astrocyte cell size and polynucleation assessment, the CellTracker dye (Thermo Fisher Scientific) was diluted 50× with PBS and incubated with cells for $20 \mathrm{~min}$ at RT. Nuclei of these cells were counterstained with TO-PRO-3 dye (Thermo Fisher Scientific). The coverslips were scanned with ScanR highcontent microscope (Olympus) and analyzed using ScanR Analysis software. The software was used for determining the cell size and counting total number of cells, polynucleated cells were counted manually.

\section{Protein Extraction and Western Blot Analysis}

Protein extraction protocols were previously described [45]. In brief, total protein from astrocytes or differentiated neurosphere cells was harvested by adding protein lysis buffer to the cell culture plates for $2 \mathrm{D}$ or by submerging the 
nanofiber scaffolds in an Eppendorf tube containing lysis buffer for Bioactive3D cell cultures. Neurospheres were collected in a $15-\mathrm{mL}$ tube and centrifuged at $300 \times \mathrm{g}$ for $5 \mathrm{~min}$, the culture medium was removed, and neurospheres washed with DPBS and resuspended in a protein lysis buffer. The protein lysis buffer was composed of $20 \mathrm{mM}$ Tris-HCL ( $\mathrm{pH} 7.5$ ), $150 \mathrm{mM} \mathrm{NaCl}, 1 \mathrm{mM}$ EDTA, $1 \% v / \mathrm{v}$ Triton-X 100, one tablet of protease inhibitor (Roche) $/ 10 \mathrm{~mL}$ lysis buffer, and one tablet of phosphatase inhibitor (Roche) $/ 10 \mathrm{~mL}$ lysis buffer. The protein lysates were sonicated for $30 \mathrm{~s}$ at 14 amplitude microns followed by protein concentration measurement by using Bio-Rad DC protein assay (Bio-Rad).

Sodium dodecyl sulfate polyacrylamide gel electrophoresis (SDS-PAGE) was performed using Any-kD polyacrylamide gels (Bio-Rad) and Tris-glycine running buffer (Bio-Rad). A total amount of $15 \mu \mathrm{g}$ of protein lysate per lane was loaded. Separated proteins were blotted on PVDF membranes $(0.2 \mu \mathrm{m}$; Millipore/Immobilon) for $2 \mathrm{~h}$ at $100 \mathrm{~V}, 300 \mathrm{~mA}$. Transfer buffer was composed of Tris-base $(2.9 \mathrm{~g} / \mathrm{L})$, glycine $(14.4 \mathrm{~g} / \mathrm{L})$, and $\mathrm{MeOH}(10 \% v / v)$ in $\mathrm{dH}_{2} \mathrm{O}$. Unspecific binding was blocked overnight at $4{ }^{\circ} \mathrm{C}$ using $3 \%$ bovine serum albumin (BSA; Sigma-Aldrich) in Tris-buffered saline containing $0.1 \%$ Tween. Incubation with primary antibodies was conducted at $4{ }^{\circ} \mathrm{C}$ overnight followed by incubation with secondary HRPlinked anti-mouse (1:2000; Cell Signaling), anti-rabbit (1:2000; Cell Signaling), or anti-goat (1:2000; Thermo Fisher Scientific) antibodies for $45 \mathrm{~min}$ at RT. Secondary HRP-linked antibodies were detected using ECL Western blotting detection reagents (GE Healthcare) and a LAS-3000 luminescent image analyzer (Fujifilm). The following primary antibodies were used: rabbit anti-GFAP (1:250; Dako) rabbit anti-vimentin (1:2000; Abacm), mouse anti-nestin (1:1500; BD Biosciences), rabbit anti-GLT-1 (1:250; Novus Biological), mouse anti- $\beta$ IIItubulin (1:1500; Covance), goat anti-SOX2 (1:200; Santa Cruz), HRP-linked anti-GAPDH (1:500; Cell Signaling), and HRP-linked anti-beta-actin (1:1500; Cell Signaling). The intensity of bands was quantified using ImageJ software and normalized to GAPDH protein levels.

\section{BrdU Injections}

For basal cell proliferation, 3-month-old male mice received a single intraperitoneal injection of $\mathrm{BrdU}(300 \mathrm{mg} / \mathrm{kg})$ in sterile saline and were killed $24 \mathrm{~h}$ later. For cell fate determination, 3month-old male mice received $\mathrm{BrdU}(300 \mathrm{mg} / \mathrm{kg})$ injection twice daily for 1 week and were killed 6 weeks after the first injection.

\section{Tissue Processing and Immunohistochemistry}

Mice were anesthetized and perfused by $4 \%$ PFA transcardially, and the dissected brains were postfixed with 4\% PFA overnight. After immersion in $30 \%$ sucrose in PBS, $30-\mu$ m-thick coronal
Fig. $1 V I M^{S A / S A}$ astrocytes exhibit well-developed intermediate filament network, normal proliferation, and scratch wound response despite lower vimentin levels. a VIM ${ }^{S A / S A}$ and $V I M^{W T W T}$ astrocytes showed comparable GFAP, nestin, and vimentin intermediate filament bundles, as assessed by immunolabeling (single and double) using antibodies against GFAP, nestin, and vimentin. b Western blot analysis showed that VIM $M^{S A / S A}$ astrocytes had unaltered expression of nestin and GLT-1 but lower expression of vimentin and higher expression of GFAP compared with $V I M^{W T}$

${ }^{W T}$ astrocytes ( $n=8$ per genotype). c VIM $M^{S A / S A}$ and VIM $M^{W T W T}$ astrocytes showed comparable cell size and contained comparable percentage of polynucleated cells $\left(n=4\right.$ per genotype). d VIM ${ }^{S A / S A}$ and $V I M^{W T / W T}$ astrocytes showed comparable proliferation and saturation cell density ( $n=4$ per genotype). e VIM ${ }^{S A / S A}$ and $V I M^{W T / W T}$ astrocytes had also comparable cell motility in vitro, as assessed by measuring the scratch wound size every $12 \mathrm{~h}(n=3$ per genotype). Data are presented as a mean \pm SEM. $* p<0.05, * * * p<0.001$. Scale bar in (a) and (c), $20 \mu \mathrm{m}$

sections were cut on a cryostat microtome. For BrdU immunohistochemistry, sections were treated first with $2 \mathrm{M} \mathrm{HCl}$ at $37{ }^{\circ} \mathrm{C}$ for $15 \mathrm{~min}$, and then blocked in 2\% BSA (Sigma-Aldrich) in DPBS supplemented with $1 \%$ Triton-X 100 (Sigma-Aldrich) at $4{ }^{\circ} \mathrm{C}$ overnight. The sections were then incubated with primary antibodies at $4{ }^{\circ} \mathrm{C}$ overnight. The following antibodies were used: rat anti-BrdU (1:200; Serotec), goat anti-doublecortin (1:50; Santa Cruz), and mouse anti-NeuN (1:200; Millipore). Fluorophore-conjugated secondary antibodies were used at a dilution of 1:1000 and incubated with the sections for $1.5 \mathrm{~h}$ at RT. Secondary antibodies used were (all from Thermo Fisher Scientific) Alexa 594-conjugated donkey anti-rat, Alexa 488conjugated donkey anti-goat, Alexa 488-conjugated donkey anti-rat, and Alexa 594-conjugated donkey anti-mouse. Cell nuclei were visualized by DAPI (Sigma-Aldrich).

\section{Hippocampal Cell Quantification}

For absolute BrdU cell quantification and colocalization of BrdU with doublecortin (DCX) or NeuN, every 6th coronal section covering the dentate gyrus within the hippocampal formation (total ten sections covering a depth of $1800 \mu \mathrm{m}$ ) were used for immunohistochemical analysis. The sections were imaged by a LSM 700 confocal microscope (Zeiss) using a tiled scan function with Z-stack optical dissections covering $25 \mu \mathrm{m}$ thickness, to capture the whole dentate gyrus area in each section. The images were analyzed by Zen 2.1 software (Zeiss). On each section, all cells positive for BrdU within the region of interest were manually quantified and assessed for NeuN or DCX immunoreactivity.

\section{Data Analysis}

Statistical analyses were performed using either Excel (Microsoft) or GraphPad Prism (Graphpad software). Twotailed $t$ test was used for comparison between two groups. Two-way ANOVA followed by post hoc analysis (Sidak correction) was conducted for multiple comparison with repeated 
A
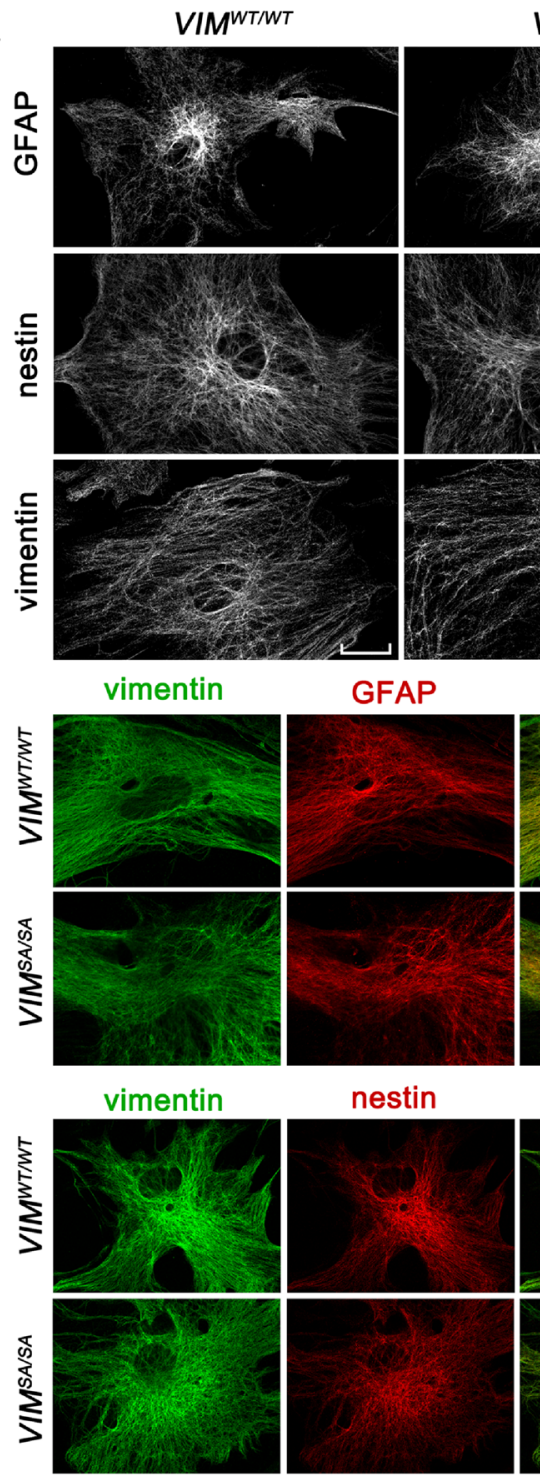

C
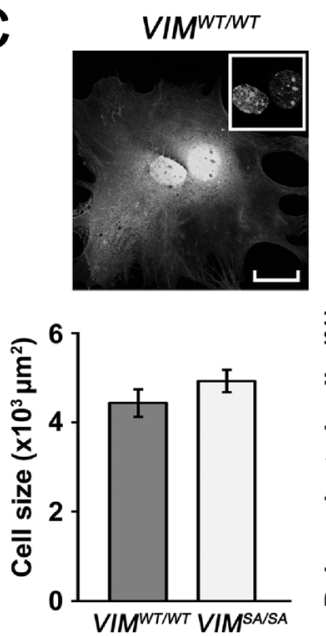
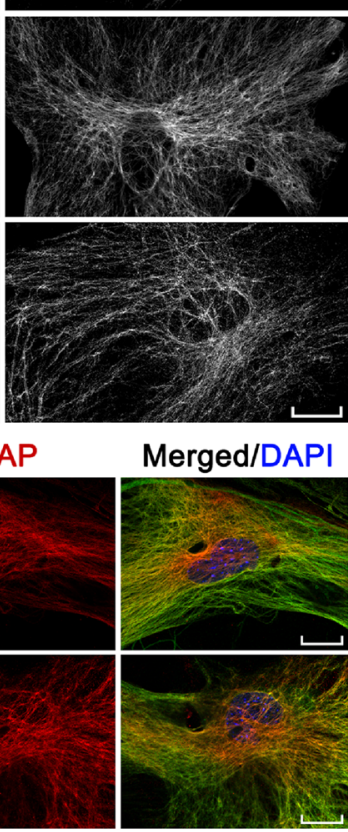

$V I M^{S A / S A}$

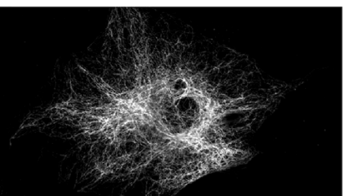

Merged/DAPI
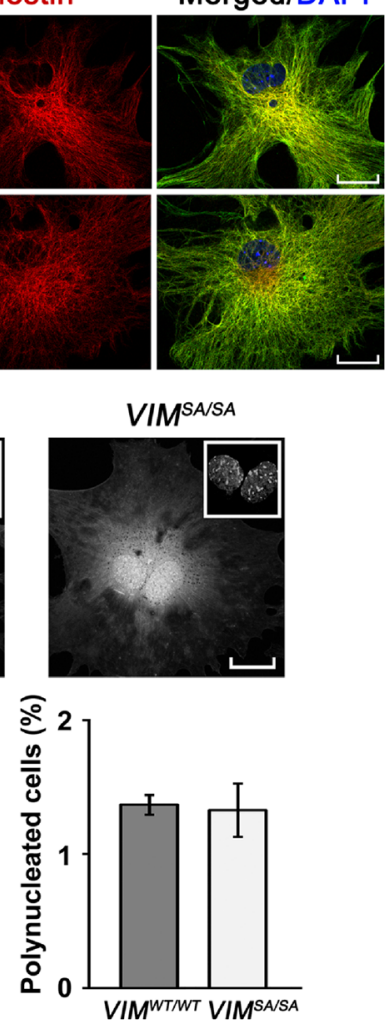

B
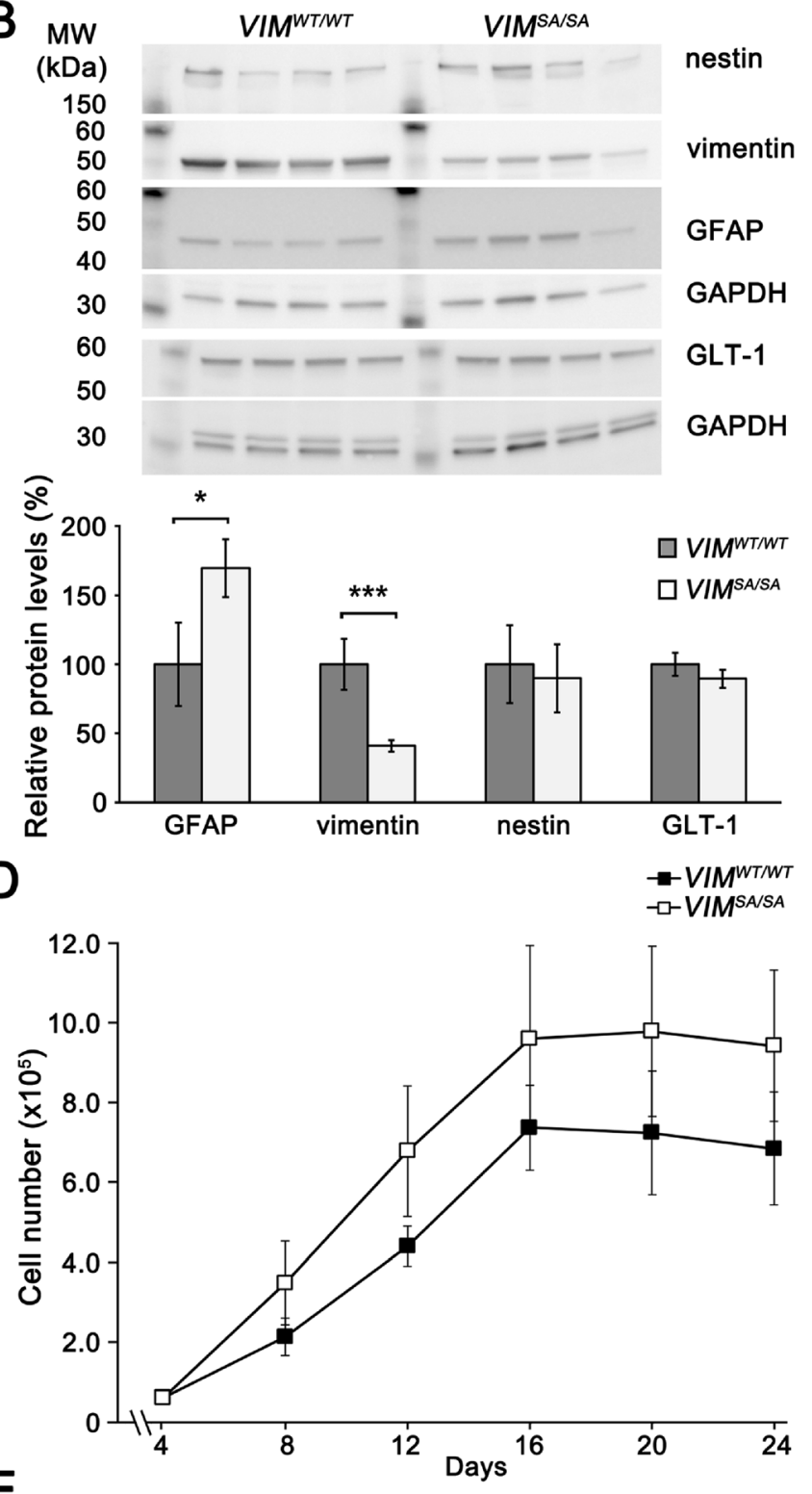

E

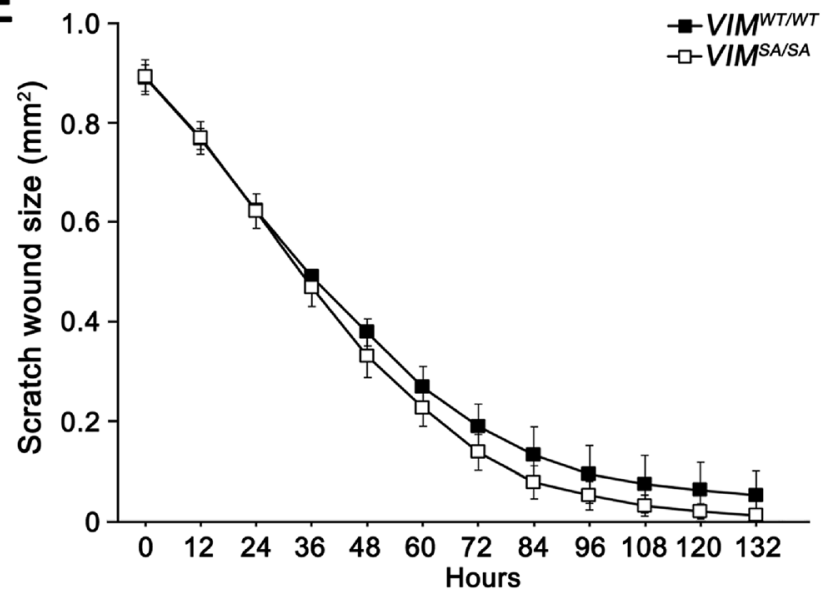


measurements. Difference were considered significant at $p<0.05$. All values were presented as mean \pm SEM.

\section{Results}

\section{$V I M^{S A / S A}$ Astrocytes Exhibit Well-Developed Intermediate Filament Network, Normal Proliferation, and Scratch Wound Response Despite Lower Vimentin Levels}

Astrocytes lacking vimentin exhibit intermediate filaments forming tightly packed bundles that are composed of only GFAP [8], altered cell morphology, and reduced motility [46]. Thus, we first examined the intermediate filament system and morphology of primary astrocytes isolated from the cortex of 2-day-old $V I M^{W T / W T}$ and $V I M^{S A / S A}$ mice. Immunolabeling of GFAP, nestin, and vimentin showed bundles of intermediate filaments that did not differ between $V I M^{W T / W T}$ and $V I M^{S A / S A}$ astrocytes (Fig. 1a). Combined immunolabeling of $V I M^{W T / W T}$ and $V I M^{S A / S A}$ astrocytes with antibodies against GFAP and vimentin, or nestin and vimentin, visualized comparable networks of intermediate filament bundles with a comparable contribution of the respective intermediate filament proteins (Fig. 1a). Western blot analysis showed lower levels of vimentin and higher levels of GFAP in $V I M^{S A / S A}$ astrocytes, while the levels of nestin and glutamate transporter GLT-1 were unaltered (Fig. 1b). VIM ${ }^{S A}$ $S A$ and $V I M^{W T / W T}$ astrocytes were of a comparable cell size (Fig. 1c). As $V I M^{S A / S A}$ fibroblasts exhibit problems with cell division [43], we next determined the fraction of astrocytes with more than one nucleus. Polynucleation was rarely observed in cultures of $V I M^{W T / W T}$ and $V I M^{S A / S A}$ astrocytes, and there was no difference in the percentage of polynucleated cells in $V I M^{W T / W T}$ and $V I M^{S A / S A}$ astrocyte cultures $(1.4 \pm 0.1 \%$ versus $1.3 \pm 0.2 \%$, respectively; Fig. $1 \mathrm{c})$. There was no difference in the proliferation and saturation cell density of $V I M^{W T / W T}$ and $V I M^{S A / S A}$ primary astrocytes, albeit the $V I M^{S A / S A}$ astrocytes exhibited a trend towards increased proliferation and higher saturation cell density (Fig. 1d).

Next, we used the scratch wound assay to assess astrocyte motility. Recordings of wound closure dynamics by live cell imaging every $12 \mathrm{~h}$ for $132 \mathrm{~h}$ did not show any difference in the wound closure between VIM $M^{W T / W T}$ and VIM ${ }^{S A / S A}$ astrocytes. These results demonstrate normal motility of $V I M^{S A / S A}$ astrocytes (Fig. 1e).

\section{$V I M^{S A / S A}$ Neurosphere Cells Show Increased Neuronal Differentiation}

Combined absence of GFAP and vimentin resulting in the absence of astrocyte cytoplasmic intermediate filament system was previously linked to increased neuronal differentiation of neurosphere cells [16] and increased hippocampal neurogenesis both in health and disease $[16,17,47]$. To determine the effects of the absence of mitotic phosphorylation sites in vimentin on neurosphere formation and differentiation, we assessed proliferation and differentiation of VIM ${ }^{S A / S A}$ and $V I M^{W T W T}$ neurosphere cells. A comparable number of primary, secondary, and quaternary neurospheres formed from the brain tissue of VIM ${ }^{S A / S A}$ and $V I M^{W T W W T}$ mice, and the cells of dissociated $V I M^{S A / S A}$ and $V I M^{W T / W T}$ neurospheres exhibited comparable proliferation (Fig. 2a). As demonstrated by immunolabeling with antibodies against nestin and vimentin, VIM $M^{S A / S A}$ and $V I M^{W T / W T}$ neurosphere cells exhibited similar nestin and vimentin immunoreactivity (Fig. 2b). However, Western blot analysis showed lower levels of vimentin in VIM ${ }^{S A / S A}$ neurosphere cells compared with VIM ${ }^{W T W T}$ and comparable levels of neural stem cell markers nestin and SOX2 (Fig. 2b).

Next, we assessed the differentiation of VIM ${ }^{S A / S A}$ and VIM $M^{W T /}$ ${ }^{W T}$ neurosphere cells, both in a standard two-dimentional (2D) cell culture system and in the 3D cell culture system (Bioactive3D) that we previously developed for astrocytes and neurons $[45,48-50]$. When allowed to differentiate in a $2 \mathrm{D}$ cell culture system, the dissociated neurosphere cells derived from $V I M^{S A / S A}$ mice were $>4$ times more likely to differentiate into $\beta$ III-tubulin ${ }^{\text {pos }}$ GFAP $^{\text {neg }}$ neurons than neurosphere cells derived from $V I M^{W T W T}$ mice $(22.1 \pm 4.8 \%$ versus $4.1 \pm 2.1 \%$, respectively; Fig. 2c). The VIM ${ }^{S A / S A}$ and VIM ${ }^{W T W T}$ neurosphere cells exhibited comparable astrocyte differentiation (Fig. 2c). The increased neuronal differentiation of VIM ${ }^{S A / S A}$ neurosphere cells was confirmed by immunostaining with antibodies against MAP2, a marker of more mature neurons compared with those visualized by antibodies against $\beta$ III-tubulin. We observed more than $100 \%$ increase in the fraction of MAP2 positive cells in $V I M^{S A / S A}$ compared with $V I M^{W T / W T}$ neurosphere cell cultures (Fig. 2d). VIM ${ }^{S A / S A}$ neurosphere cells differentiating in the Bioactive3D cell culture system generated less astrocytes than in the 2D system (Fig. 2c, e). Similar to the 2D culture system, in Bioactive3D, neurosphere cells derived from VIM ${ }^{S A / S A}$ mice were $>3$ times more likely to differentiate into $\beta$ IIItubulin ${ }^{\text {pos }}$ GFAP $^{\text {neg }}$ neurons than neurosphere cells derived from $V I M^{W T W T}$ mice $(30.4 \pm 6.9 \%$ versus $10.0 \pm 4.4 \%$, respectively; Fig. 2e), while $V I M^{S A / S A}$ and $V I M^{W T W T}$ neurosphere cells exhibited comparable astrocyte differentiation (Fig. 2e). The increased neuronal differentiation potential of VIM ${ }^{S A / S A}$ neurosphere cells in both culture systems was further supported by the $\beta$ III-tubulin levels on Western blot in pooled protein lysates from cultures of differentiating $V I M^{S A / S A}$ neurosphere cells compared with $V I M^{W T / W T}$ (Fig. 2f).

\section{The Pro-neurogenic Properties of $V I M^{S A / S A}$ Neurosphere Cells Are Not Affected by the Astrocyte Environment}

We previously reported that reduced Notch signaling from intermediate filament-free astrocytes increased neuronal 
A
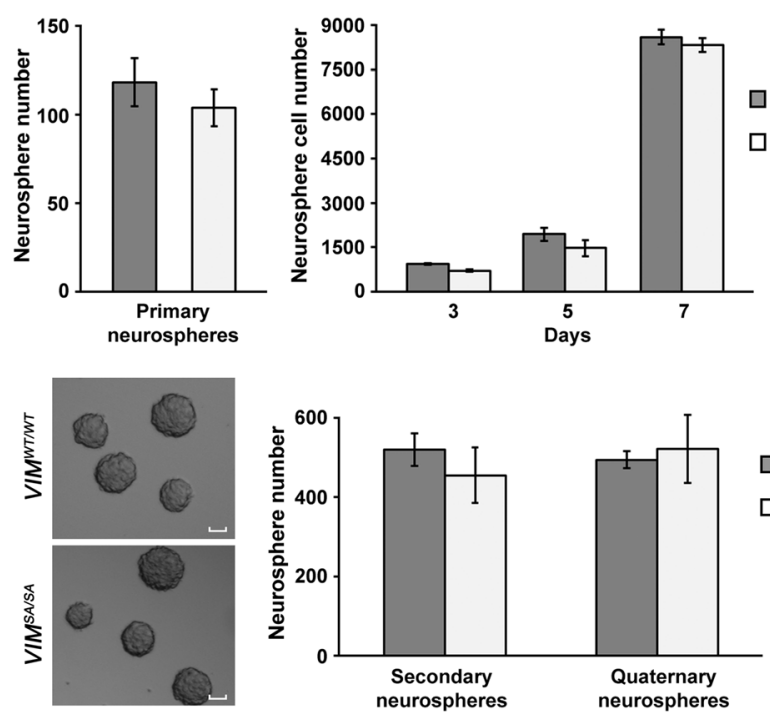

B
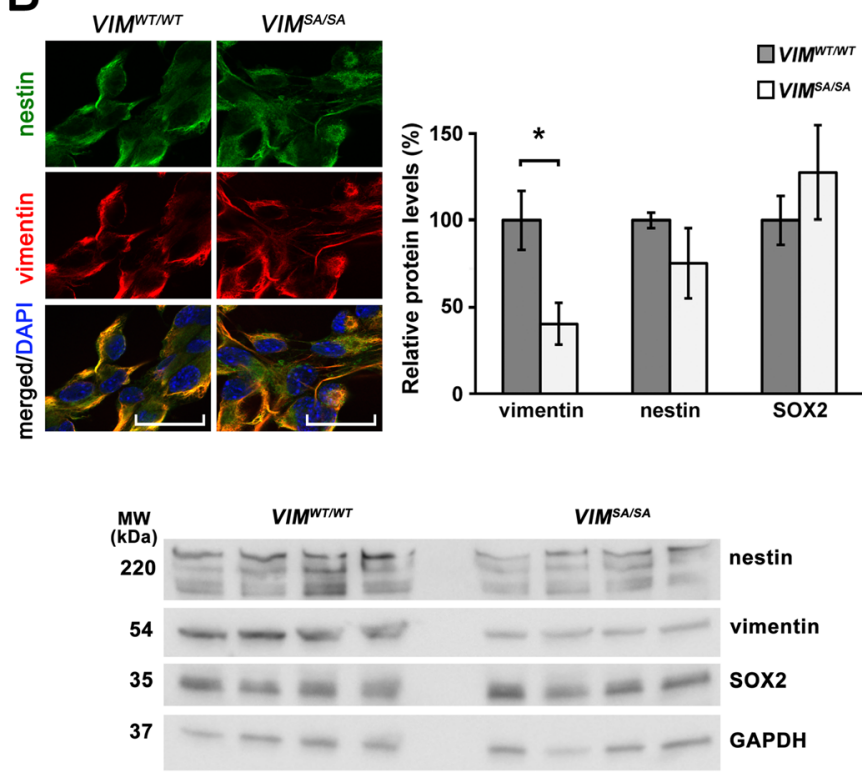

Fig. $2 V I M^{S A / S A}$ neurosphere cells show increased neuronal differentiation. a $V I M^{S A / S A}$ and $V I M^{W T / W T}$ brain cells showed comparable neurosphere forming capacity (assessed for primary, secondary, and quaternary neurospheres) and $V I M^{S A / S A}$ and $V I M^{W T / W T}$ neurosphere cells showed comparable proliferation. The data show the total number of neurospheres formed from 50,000 plated cells $(n=4$ per genotype) and the number of neurosphere cells generated from primary dissociated neurospheres ( $n=4$ per genotype). b VIM ${ }^{S A / S A}$ and $V I M^{W T / W T}$ neurosphere cells showed comparable vimentin and nestin immunoreactivity. Western blot analysis showed comparable expression of nestin and SOX-2 but lower expression of vimentin in VIM ${ }^{S A / S A}$ neurosphere cells compared with $V I M^{W T W T}$ ( $n=4$ per genotype). c-e To assess the neuronal differentiation, dissociated neurosphere cells were allowed to differentiate, and double-immunolabeled with neuronal

differentiation of neural progenitor cells [16, 21]. Therefore, we next sought to determine whether the increase in neuronal
C
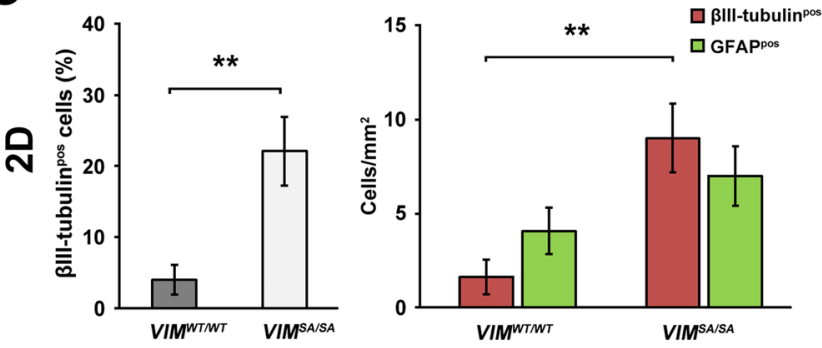

D
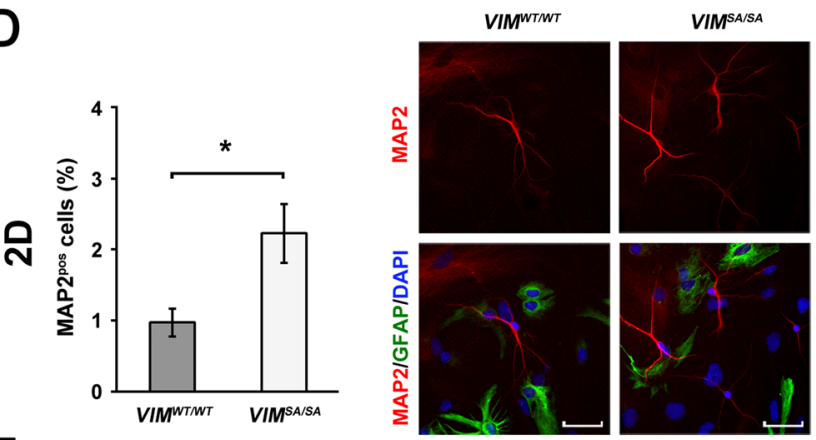

E
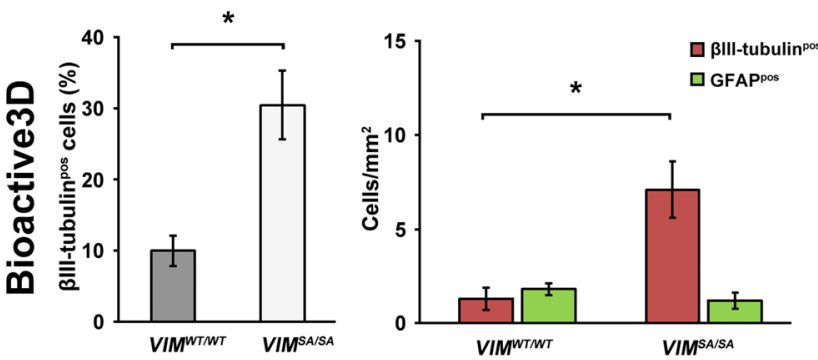

F

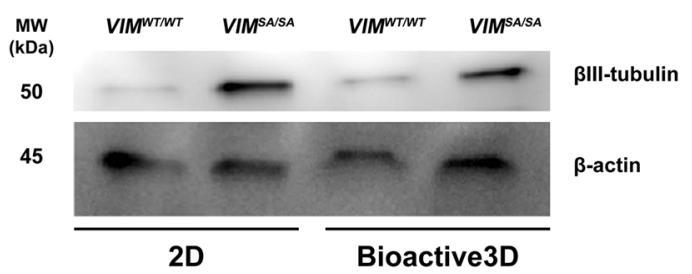

makers $\beta$ III-tubulin or MAP2, and astrocyte marker GFAP. VIM ${ }^{S A / S A}$ neurosphere cells showed highly increased relative (left) and absolute (right) neuronal differentiation compared with $V I M^{W T / W T}$ neurosphere cells in both $2 \mathrm{D}$ and Bioactive3D culture system $(n=5$ per genotype in 2D system, $n=4$ per genotype in Bioactive3D system; $\mathbf{c}, \mathbf{e}$, respectively). $V I M^{\text {SA/SA }}$ neurosphere cells showed also twofold increase of neuronal differentiation in 2D culture system when the neurons were immunolabeled with antibody against MAP2 (d). f Western blot indicates higher expression level of $\beta$ III-tubulin in differentiated $V I M^{S A / S A}$ neurosphere cells than in differentiated VIM ${ }^{W T W T}$ neurosphere cells, in both $2 \mathrm{D}$ and $3 \mathrm{D}$ culture systems ( $n=1$ per genotype, pooled lysates from four samples). Data are presented as a mean \pm SEM. ${ }^{*} p<0.05$; ${ }^{* *} p<0.01$. Scale bar in (a) and (d), $50 \mu \mathrm{m}$. Scale bar in (b), $20 \mu \mathrm{m}$

differentiation of $V I M^{S A / S A}$ neurosphere cells was neurosphere cell intrinsic or caused by the niche of VIM ${ }^{S A / S A}$ astrocytes. We 
A

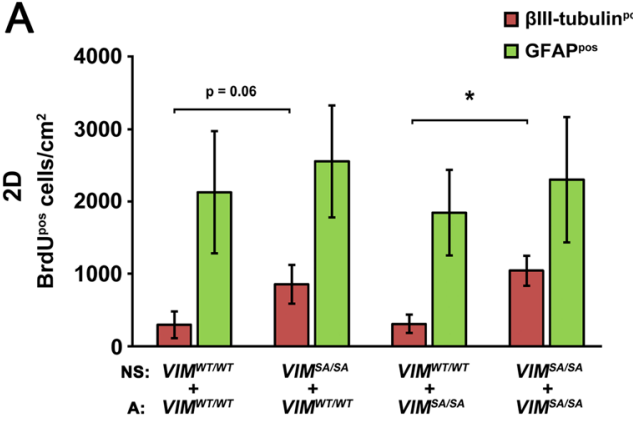

B

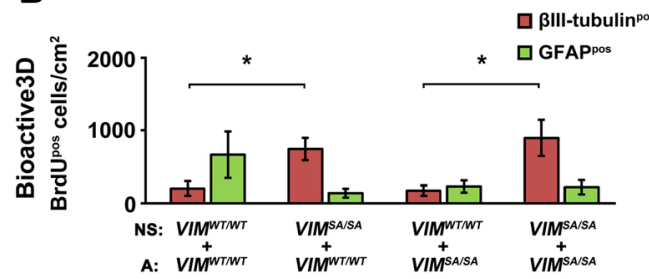

Fig. 3 The pro-neurogenic properties of VIM ${ }^{S A / S A}$ neurosphere cells are not affected by the astrocyte environment. a, b Dissociated VIM ${ }^{W T W T}$ or $V I M^{S A / S A}$ neurosphere cells pre-labeled with BrdU cocultured with $V I M^{W T W T}$ or VIM ${ }^{S A / S A}$ astrocytes in 2D (a) and Bioactive3D (b) culture systems. The graphs show the absolute number of immunolabeled neu-

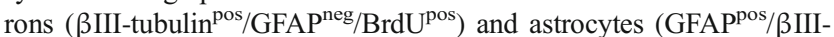
tubulin $\left.^{\text {neg }} / \mathrm{BrdU}^{\text {pos }}\right)$ per square millimeter $(n=5$ per genotype in $2 \mathrm{D}$ cultures, $n=4$ per genotype in Bioactive3D cultures; $\mathbf{a}, \mathbf{b}$, respectively). Data are presented as a mean \pm SEM. $* p<0.05$. NS, neurosphere cells; $A$, astrocytes

assessed neurogenesis and astrogenesis from $V I M^{S A / S A}$ and $V I M^{W T / W T}$ neurosphere cells in cocultures of primary neurospheres, pre-labeled with BrdU for $48 \mathrm{~h}$, and passage 1 astrocytes. In the $2 \mathrm{D}$ cell culture system, VIM ${ }^{\text {SA } / S A}$ neurosphere cells gave rise to more neurons than $V I M^{W T W T}$ neurosphere cells when cocultured with VIM ${ }^{\text {SA } / S A}$ astrocytes $(10.4 \pm 2.1$ cells $/ \mathrm{mm}^{2}$ versus $3.1 \pm 1.3$ cells $/ \mathrm{mm}^{2}$, respectively; Fig. 3a). Similarly, in the Bioactive3D cell culture system, VIM ${ }^{S A / S A}$ neurosphere cells gave rise to more neurons than $V I M^{W T W T}$ neurosphere cells, irrespective of whether they were cocultured with $V I M^{W T W T}\left(7.4 \pm 1.5 \mathrm{cells} / \mathrm{mm}^{2}\right.$ versus $2.0 \pm 1.0$ cells/ $\mathrm{mm}^{2}$, respectively) or $V I M^{S A / S A}$ astrocytes $(9.0 \pm 2.5$ cells/ $\mathrm{mm}^{2}$ versus $1.7 \pm 0.7$ cells $/ \mathrm{mm}^{2}$, respectively; Fig. $3 \mathrm{~b}$ ). The astrocyte environment did not affect astrogenesis from neurosphere cells in any of the coculture systems (Fig. 3a, b). These results suggest that the increased neuronal differentiation of VIM ${ }^{\text {SA } / S A}$ neurosphere cells is a cell intrinsic phenomenon.

\section{$V I M^{S A / S A}$ Mice Exhibit a Modest Increase in the Fraction of Newly Born and Surviving Neurons in the Hippocampal Dentate Gyrus}

To ascertain whether the increased neuronal differentiation of $V I M^{S A / S A}$ neurosphere cells in vitro translates into increased neurogenesis in the brains of $V I M^{S A / S A}$ mice, we used BrdU in vivo labeling and quantified neural stem cell proliferation and neurogenesis in the hippocampal dentate gyrus, one of the two major neurogenic regions of the adult brain. Twenty-four hours after a single injection of $\mathrm{BrdU}, V I M^{S A / S A}$ mice had higher percentage of $\mathrm{DCX}^{\mathrm{pos}} \mathrm{BrdU}^{\mathrm{pos}}$ neuroblasts in the dentate gyrus of the hippocampus $(41.9 \pm 0.9 \%$ versus $37.6 \pm 1.2 \%$ of the $\mathrm{BrdU}^{\mathrm{pos}}$ cells, respectively); however, the absolute numbers of BrdU ${ }^{\text {pos }}$ cells and $\mathrm{DCX}^{\mathrm{pos}} \mathrm{BrdU}^{\mathrm{pos}}$ neuroblasts was comparable in VIM ${ }^{W T W T}$ and VIM ${ }^{S A / S A}$ mice (Fig. 4a).

Six weeks following BrdU labeling, the percentage of the newly born and surviving NeuN ${ }^{\text {pos }} \mathrm{BrdU}^{\text {pos }}$ neurons in $V I M^{S A}$ ${ }^{S A}$ mice was increased by $8 \%(66.3 \pm 1.0 \%$ versus $71.7 \pm 1.1 \%$ of the $\mathrm{BrdU}^{\text {pos }}$ cells; Fig. 4b). VIM ${ }^{\text {SA/SA }}$ mice had lower absolute number $\mathrm{BrdU}^{\text {pos }}$ cells ( $488 \pm 16$ versus $586 \pm 33$, respectively), and the absolute numbers of newly born and surviving NeuN ${ }^{\text {pos }} \mathrm{BrdU}^{\text {pos }}$ neurons were comparable between the two groups (390 \pm 26 versus $351 \pm 14$, respectively; Fig. 4b).

\section{Discussion}

Our results show that mutation of the serine sites that are phosphorylated during mitosis in the intermediate filament protein vimentin results in lower levels of vimentin and higher levels of GFAP in VIM ${ }^{S A / S A}$ astrocytes but does not affect the appearance and distribution of the intermediate filament network, astrocyte morphology, proliferation, presence of multiple cell nuclei, and astrocyte motility. Thus, phosphorylation of vimentin during mitosis does not seem to play a major role in the control of morphology, cell division, and motility of astrocytes. This is in contrast with $V I M^{S A / S A}$ lens epithelial cells or fibroblasts that showed disrupted intermediate filament network and formation of unbreakable intermediate filament bridges during mitosis. Lower levels of vimentin in $V I M^{S A / S A}$ astrocytes apparently do not affect the appearance and function of the intermediate filament network in these cells. Vimentin network is highly dynamic with an active subunit exchange between polymers and soluble subunits [51], and it is conceivable that deficit in vimentin phosphorylation affects the equilibrium between the polymerized and unpolymerized intermediate filament proteins and consequently leads to increased degradation of soluble vimentin subunits. Functionally deficient intermediate filament network in $V I M^{S A / S A}$ lens epithelial cells and fibroblasts was linked to the increased incidence of polynucleation observed in these cells $[42,43]$. The presence of an intact intermediate filament network in VIM ${ }^{S A / S A}$ astrocytes is compatible with the normal incidence of polynucleation in these cells. Vimentin is highly expressed in astrocytes, lens epithelial cells and fibroblasts. In astrocytes, vimentin forms intermediate filaments together with GFAP and nestin. Given that GFAP 

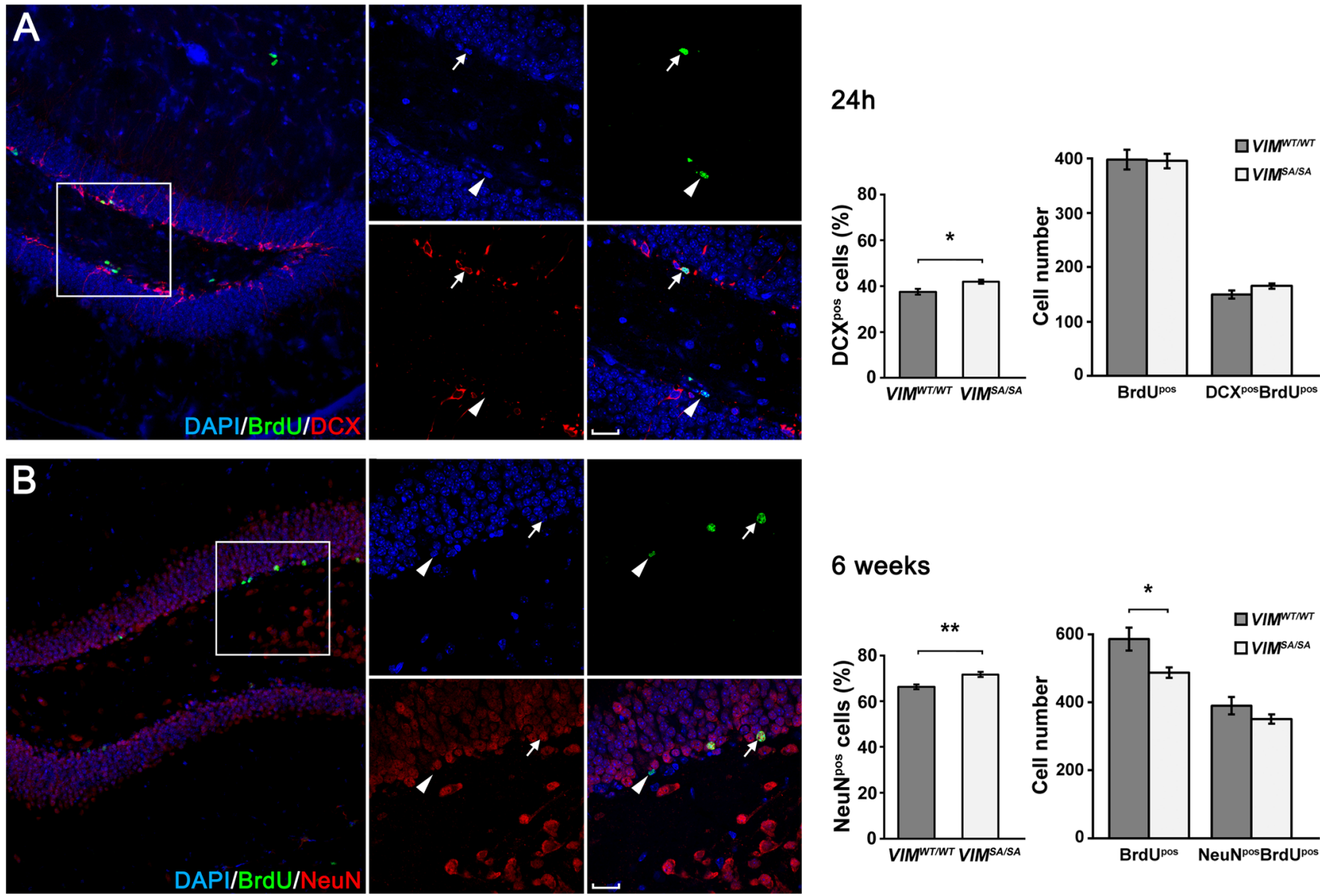

Fig. $4 V I M^{S A / S A}$ mice exhibit a modest increase in the fraction of newly born and surviving neurons in the hippocampal dentate gyrus. a Image of dentate gyrus immunostained with antibodies against doublecortin $(D C X)$ and BrdU; the nuclei were visualized with DAPI. Arrow, $\mathrm{DCX}^{\mathrm{pos}} \mathrm{BrdU}^{\mathrm{pos}}$ cell; arrowhead, $\mathrm{DCX}^{\text {neg }} \mathrm{BrdU}^{\text {pos }}$ cell. VIM ${ }^{S A / S A}$ mice had higher percentage of $\mathrm{DCX}^{\text {pos }} \mathrm{BrdU}^{\text {pos }}$ neuroblasts among the proliferation cells $\left(\mathrm{BrdU}^{\text {pos }}\right.$ ) in the dentate gyrus, but the absolute numbers of BrdU ${ }^{\text {pos }}$ cells and $\mathrm{DCX}^{\text {pos }} \mathrm{BrdU}^{\text {pos }}$ neuroblasts were comparable in $V I M^{W T / W T}$ and $V I M^{S A / S A}$ mice. Ten serial coronal brain sections with a $180-\mu \mathrm{m}$ intersection distance analyzed per mouse, $n=5$ per genotype. b Image of dentate gyrus immunostained with antibodies against NeuN and BrdU.
The nuclei were visualized with DAPI. Arrow, NeuN ${ }^{\text {pos }} \mathrm{BrdU}^{\text {pos }}$ cell; arrowhead, $\mathrm{NeuN}^{\text {neg }} \mathrm{BrdU}^{\text {pos }}$ cell. VIM ${ }^{S A / S A}$ mice showed higher percentage of neurons $\left(\mathrm{NeuN}^{\mathrm{pos}} \mathrm{BrdU}^{\text {pos }}\right.$ ) among surviving newly born cells (BrdU $\left.{ }^{\text {pos }}\right)$, but the absolute number of surviving newly born neurons was comparable between the genotypes. VIM ${ }^{S A / S A}$ mice showed decreased absolute number of surviving newly born cells $\left(\mathrm{BrdU}^{\mathrm{pos}}\right)$. Ten serial coronal brain sections with a $180 \mu \mathrm{m}$ inter-section distance analyzed per mouse, $n=10$ per genotype. Data are presented as a mean \pm SEM. $* p<0.05 ; * * p<0.01$. The inlets in (a) and (b) show individual fluorescence channels. Scale bar in (a) and (b), $20 \mu \mathrm{m}$ is highly expressed in postnatal astrocytes but not in lens epithelial cells or fibroblasts [42, 43, 52], and that GFAP expression levels were increased in $V I M^{S A / S A}$ astrocytes, it is possible that in VIM $M^{S A / S A}$ astrocytes, GFAP compensates for the potential dysfunction of vimentin. Compensation by GFAP is conceivably also the explanation for the normal appearance of the intermediate filament network in VIM ${ }^{S A / S A}$ astrocytes, in contrast with the prominent changes of the intermediate filament system in VIM ${ }^{S A S A}$ epithelial cells.

We previously reported that the absence of GFAP and vimentin (but not of only GFAP or of only vimentin) led to decreased Notch signaling from astrocytes to neural progenitor cells $[16,21]$ and increased neuronal differentiation of these cells [16] as well as increased hippocampal neurogenesis in mice devoid of astrocyte intermediate filaments, both in health and disease $[16,17,47]$. Here, we observed increased neuronal differentiation of $V I M^{S A / S A}$ neurosphere cells and determined that the pro-neurogenic properties of VIM ${ }^{S A / S A}$ neurosphere cells were not due to astrocyte environment but were neurosphere cell intrinsic.

In both $2 \mathrm{D}$ and Bioactive3D cell culture systems, VIM ${ }^{S A / S A}$ neurosphere cells showed highly increased neuronal differentiation (two- to fourfold), but the fraction of newly formed and surviving neurons in the hippocampal dentate gyrus of the VIM ${ }^{\text {SA/SA }}$ mice was only modestly increased (by $8 \%$ ). Thus, the in vitro effect of VIM ${ }^{S A / S A}$ mutation can be mitigated or 
masked in vivo by niche-related factors that remain to be identified. It is interesting to point out that the Bioactive3D culture system, which maintains aspects of in vivo-like morphology of the cultured neural cells (astrocytes and neurons) and reduces the baseline reactivity of astrocytes as well as their proliferation $[45,48-50]$, led to lower numbers of astrocytes in the neurosphere cell differentiation assays, as well as in cocultures of astrocytes/neurosphere cells. Nevertheless, even in Bioactive3 $\mathrm{D}$, a cell culture system closer to the in vivo situation, the increased neurogenesis from neurosphere cells was very robust and more prominent compared with only modestly increased hippocampal neurogenesis in VIM ${ }^{S A / S A}$ mice, conceivably due to the absence of other niche constituents such as endothelial cells and microglia in the in vitro system.

In conclusion, our main finding is that VIM $M^{S A / S A}$ astrocytes do not show any major phenotypic changes, but VIM ${ }^{S A / S A}$ neurospheres exhibit highly increased neuronal differentiation; this effect is neurosphere cell intrinsic and not dependent on the astrocyte niche. VIM ${ }^{S A / S A}$ mice show a modest increase in the fraction of newly born and surviving neurons in the hippocampal dentate gyrus. The functional significance of this finding and the involvement of phosphovimentin in the functions of other cells that express vimentin in the neurogenic niche, such as the endothelial cells and microglia, warrant further investigation.

Acknowledgments This work was supported by Swedish Medical Research Council (11548), ALF Gothenburg (11392), AFA Research Foundation, Söderberg's Foundations, Sten A. Olsson Foundation for Research and Culture, Hjärnfonden, Hagströmer's Foundation Millennium, Amlöv's Foundation, E. Jacobson's Donation Fund, Wilhelm and Martina Lundgrens Foundation, VINNOVA Health Program, the Swedish Stroke Foundation, the Swedish Society of Medicine, NanoNet COST Action (BM1002), EU FP 7 Program EduGlia (237956), and EU FP 7 Program TargetBraIn (279017). Some of the imaging equipment used here is placed at the Centre for Cellular Imaging at the Sahlgrenska Academy, University of Gothenburg.

Author's Contribution Meng Chen is responsible for planning, conducting, evaluating, and interpreting the experiments and manuscript writing. Till B. Puschmann is responsible for planning, conducting, evaluating, and interpreting the experiments and manuscript revision. Pavel Marasek is responsible for planning, conducting, evaluating, and interpreting the experiments and manuscript revision. Masaki Inagaki is responsible for providing the VIM ${ }^{S A / S A}$ mice to establish the colony needed for these experiments and manuscript revision. Marcela Pekna is responsible for evaluating and interpreting the experiments and manuscript writing. Ulrika Wilhelmsson is responsible for planning, conducting, evaluating, and interpreting the experiments and manuscript writing. Milos Pekny is responsible for planning, evaluating, and interpreting the experiments and manuscript writing.

\section{Compliance with Ethical Standards}

Conflict of Interest The authors declare that they have no conflict of interest.
Open Access This article is distributed under the terms of the Creative Commons Attribution 4.0 International License (http:// creativecommons.org/licenses/by/4.0/), which permits unrestricted use, distribution, and reproduction in any medium, provided you give appropriate credit to the original author(s) and the source, provide a link to the Creative Commons license, and indicate if changes were made.

\section{References}

1. Pekny M, Wilhelmsson U, Pekna M (2014) The dual role of astrocyte activation and reactive gliosis. Neurosci Lett 565:30-38. https://doi.org/10.1016/j.neulet.2013.12.071

2. Pekny M, Nilsson M (2005) Astrocyte activation and reactive gliosis. Glia 50(4):427-434. https://doi.org/10.1002/glia.20207

3. Verkhratsky A, Parpura V, Pekna M, Pekny M, Sofroniew M (2014) Glia in the pathogenesis of neurodegenerative diseases. Biochem Soc Trans 42:1291-1301. https://doi.org/10.1042/Bst20140107

4. Pekny M, Pekna M (2014) Astrocyte reactivity and reactive astrogliosis: costs and benefits. Physiol Rev 94(4):1077-1098. https://doi.org/10.1152/physrev.00041.2013

5. Pekny M, Pekna M, Messing A, Steinhauser C, Lee JM, Parpura V, Hol EM, Sofroniew MV et al (2016) Astrocytes: a central element in neurological diseases. Acta Neuropathol 131(3):323-345. https://doi.org/10.1007/s00401-015-1513-1

6. Khakh BS, Sofroniew MV (2015) Diversity of astrocyte functions and phenotypes in neural circuits. Nat Neurosci 18(7):942-952. https://doi.org/10.1038/nn.4043

7. Pekny M, Johansson CB, Eliasson C, Stakeberg J, Wallen A, Perlmann T, Lendahl U, Betsholtz C et al (1999) Abnormal reaction to central nervous system injury in mice lacking glial fibrillary acidic protein and vimentin. J Cell Biol 145(3):503-514

8. Eliasson C, Sahlgren C, Berthold CH, Stakeberg J, Celis JE, Betsholtz C, Eriksson JE, Pekny M (1999) Intermediate filament protein partnership in astrocytes. J Biol Chem 274(34):2399624006

9. Wilhelmsson U, Li L, Pekna M, Berthold CH, Blom S, Eliasson C, Renner O, Bushong E et al (2004) Absence of glial fibrillary acidic protein and vimentin prevents hypertrophy of astrocytic processes and improves post-traumatic regeneration. J Neurosci 24(21):50165021

10. Cho KS, Yang L, Lu B, Feng Ma H, Huang X, Pekny M, Chen DF (2005) Re-establishing the regenerative potential of central nervous system axons in postnatal mice. J Cell Sci 118(Pt 5):863-872. https://doi.org/10.1242/jcs.01658

11. Menet V, Prieto M, Privat A, Gimenez y Ribotta M (2003) Axonal plasticity and functional recovery after spinal cord injury in mice deficient in both glial fibrillary acidic protein and vimentin genes. Proc Natl Acad Sci U S A 100(15):8999-9004

12. Verardo MR, Lewis GP, Takeda M, Linberg KA, Byun J, Luna G, Wilhelmsson U, Pekny M et al (2008) Abnormal reactivity of muller cells after retinal detachment in mice deficient in GFAP and vimentin. Invest Ophthalmol Vis Sci 49(8):3659-3665

13. Lundkvist A, Reichenbach A, Betsholtz C, Carmeliet P, Wolburg H, Pekny M (2004) Under stress, the absence of intermediate filaments from Muller cells in the retina has structural and functional consequences. J Cell Sci 117(16):3481-3488. https://doi.org/10.1242/jcs. 01221

14. Kinouchi R, Takeda M, Yang L, Wilhelmsson U, Lundkvist A, Pekny M, Chen DF (2003) Robust neural integration from retinal transplants in mice deficient in GFAP and vimentin. Nat Neurosci 6(8):863-868. https://doi.org/10.1038/nn1088 
15. Widestrand A, Faijerson J, Wilhelmsson U, Smith PL, Li L, Sihlbom C, Eriksson PS, Pekny M (2007) Increased neurogenesis and astrogenesis from neural progenitor cells grafted in the hippocampus of $\mathrm{GFAP}^{-/} \mathrm{Vim}^{-/}$mice. Stem Cells 25(10):2619-2627. https://doi.org/10.1634/stemcells.2007-0122

16. Wilhelmsson U, Faiz M, de Pablo Y, Sjoqvist M, Andersson D, Widestrand A, Potokar M, Stenovec M et al (2012) Astrocytes negatively regulate neurogenesis through the JAGGED1-mediated notch pathway. Stem Cells 30(10):2320-2329. https://doi.org/10. 1002/stem.1196

17. Jarlestedt K, Rousset CI, Faiz M, Wilhelmsson U, Stahlberg A, Sourkova H, Pekna M, Mallard C et al (2010) Attenuation of reactive gliosis does not affect infarct volume in neonatal hypoxicischemic brain injury in mice. PLoS One 5(4):e10397. https://doi. org/10.1371/journal.pone.0010397

18. Pekny M, Lane EB (2007) Intermediate filaments and stress. Exp Cell Res 313(10):2244-2254. https://doi.org/10.1016/j.yexcr.2007. 04.023

19. de Pablo Y, Nilsson M, Pekna M, Pekny M (2013) Intermediate filaments are important for astrocyte response to oxidative stress induced by oxygen-glucose deprivation and reperfusion. Histochem Cell Biol 140(1):81-91. https://doi.org/10.1007/ s00418-013-1110-0

20. Shinjyo N, de Pablo Y, Pekny M, Pekna M (2016) Complement peptide C3a promotes astrocyte survival in response to ischemic stress. Mol Neurobiol 53(5):3076-3087. https://doi.org/10.1007/ s12035-015-9204-4

21. Lebkuechner I, Wilhelmsson U, Mollerstrom E, Pekna M, Pekny M (2015) Heterogeneity of notch signaling in astrocytes and the effects of GFAP and vimentin deficiency. J Neurochem 135(2):234248. https://doi.org/10.1111/jnc.13213

22. Herrmann H, Aebi U (1998) Intermediate filament assembly: Fibrillogenesis is driven by decisive dimer-dimer interactions. Curr Opin Struct Biol 8(2):177-185

23. Herrmann H, Bar H, Kreplak L, Strelkov SV, Aebi U (2007) Intermediate filaments: From cell architecture to nanomechanics. Nat Rev Mol Cell Biol 8(7):562-573. https://doi.org/10.1038/ nrm2197

24. Inagaki M, Matsuoka $\mathrm{Y}$, Tsujimura $\mathrm{K}$, Ando S, Tokui T, Takahashi T, Inagaki N (1996) Dynamic property of intermediate filaments: regulation by phosphorylation. BioEssays 18(6):481-487. https:// doi.org/10.1002/bies. 950180610

25. Ivaska J, Pallari HM, Nevo J, Eriksson JE (2007) Novel functions of vimentin in cell adhesion, migration, and signaling. Exp Cell Res 313(10):2050-2062. https://doi.org/10.1016/j.yexcr.2007.03.040

26. Omary MB, Ku NO, Tao GZ, Toivola DM, Liao J (2006) 'Heads and tails' of intermediate filament phosphorylation: multiple sites and functional insights. Trends Biochem Sci 31(7):383-394. https://doi.org/10.1016/j.tibs.2006.05.008

27. Sihag RK, Inagaki M, Yamaguchi T, Shea TB, Pant HC (2007) Role of phosphorylation on the structural dynamics and function of types III and IV intermediate filaments. Exp Cell Res 313(10): 2098-2109. https://doi.org/10.1016/j.yexcr.2007.04.010

28. Goto H, Yasui Y, Kawajiri A, Nigg EA, Terada Y, Tatsuka M, Nagata K, Inagaki M (2003) Aurora-B regulates the cleavage furrow-specific vimentin phosphorylation in the cytokinetic process. J Biol Chem 278(10):8526-8530. https://doi.org/10.1074/ jbc.M210892200

29. Kawajiri A, Yasui Y, Goto H, Tatsuka M, Takahashi M, Nagata K, Inagaki M (2003) Functional significance of the specific sites phosphorylated in desmin at cleavage furrow: Aurora-B may phosphorylate and regulate type III intermediate filaments during cytokinesis coordinatedly with Rho-kinase. Mol Biol Cell 14(4):1489-1500. https://doi.org/10.1091/mbc.E02-09-0612

30. Yamaguchi T, Goto H, Yokoyama T, Sillje H, Hanisch A, Uldschmid A, Takai Y, Oguri T et al (2005) Phosphorylation by
Cdk1 induces Plk1-mediated vimentin phosphorylation during mitosis. J Cell Biol 171(3):431-436. https://doi.org/10.1083/jcb. 200504091

31. Yasui Y, Goto H, Matsui S, Manser E, Lim L, Nagata K, Inagaki M (2001) Protein kinases required for segregation of vimentin filaments in mitotic process. Oncogene 20(23):2868-2876. https:// doi.org/10.1038/sj.onc. 1204407

32. Yasui $Y$, Amano M, Nagata K, Inagaki N, Nakamura H, Saya H, Kaibuchi K, Inagaki M (1998) Roles of Rho-associated kinase in cytokinesis; mutations in Rho-associated kinase phosphorylation sites impair cytokinetic segregation of glial filaments. J Cell Biol 143(5):1249-1258. https://doi.org/10.1083/jcb.143.5.1249

33. Tsujimura K, Ogawara M, Takeuchi Y, Imajoh-Ohmi S, Ha MH, Inagaki M (1994) Visualization and function of vimentin phosphorylation by cdc2 kinase during mitosis. J Biol Chem 269(49):3109731106

34. Chou YH, Bischoff JR, Beach D, Goldman RD (1990) Intermediate filament reorganization during mitosis is mediated by $\mathrm{p} 34 \mathrm{cdc} 2$ phosphorylation of vimentin. Cell 62(6):1063-1071

35. Goto H, Kosako H, Tanabe K, Yanagida M, Sakurai M, Amano M, Kaibuchi K, Inagaki M (1998) Phosphorylation of vimentin by Rho-associated kinase at a unique amino-terminal site that is specifically phosphorylated during cytokinesis. J Biol Chem 273(19): 11728-11736

36. Kosako H, Amano M, Yanagida M, Tanabe K, Nishi Y, Kaibuchi K, Inagaki M (1997) Phosphorylation of glial fibrillary acidic protein at the same sites by cleavage furrow kinase and Rho-associated kinase. J Biol Chem 272(16):10333-10336

37. Inada H, Togashi H, Nakamura Y, Kaibuchi K, Nagata K, Inagaki M (1999) Balance between activities of Rho kinase and type 1 protein phosphatase modulates turnover of phosphorylation and dynamics of desmin/vimentin filaments. J Biol Chem 274(49): 34932-34939

38. Goto H, Inagaki M (2007) Production of a site- and phosphorylation state-specific antibody. Nat Protoc 2(10):2574-2581. https:// doi.org/10.1038/nprot.2007.374

39. Nishizawa $\mathrm{K}$, Yano $\mathrm{T}$, Shibata $\mathrm{M}$, Ando $\mathrm{S}$, Saga $\mathrm{S}$, Takahashi $\mathrm{T}$, Inagaki M (1991) Specific localization of Phosphointermediate filament protein in the constricted area of dividing cells. J Biol Chem 266(5):3074-3079

40. Ogawara M, Inagaki N, Tsujimura K, Takai Y, Sekimata M, Ha MH, Imajoh-Ohmi S, Hirai S et al (1995) Differential targeting of protein kinase $\mathrm{C}$ and $\mathrm{CaM}$ kinase II signalings to vimentin. J Cell Biol 131(4):1055-1066

41. Inagaki N, Goto H, Ogawara M, Nishi Y, Ando S, Inagaki M (1997) Spatial patterns of $\mathrm{Ca} 2+$ signals define intracellular distribution of a signaling by $\mathrm{Ca} 2+/$ calmodulin-dependent protein kinase II. J Biol Chem 272(40):25195-25199

42. Matsuyama M, Tanaka H, Inoko A, Goto H, Yonemura S, Kobori K, Hayashi Y, Kondo E et al (2013) Defect of mitotic vimentin phosphorylation causes microophthalmia and cataract via aneuploidy and senescence in lens epithelial cells. J Biol Chem 288(50): 35626-35635. https://doi.org/10.1074/jbc.M113.514737

43. Tanaka H, Goto H, Inoko A, Makihara H, Enomoto A, Horimoto K, Matsuyama M, Kurita K et al (2015) Cytokinetic failure-induced tetraploidy develops into aneuploidy, triggering skin aging in Phosphovimentin-deficient mice. J Biol Chem 290(21):1298412998. https://doi.org/10.1074/jbc.M114.633891

44. Pekny M, Eliasson C, Chien CL, Kindblom LG, Liem R, Hamberger A, Betsholtz C (1998) GFAP-deficient astrocytes are capable of stellation in vitro when cocultured with neurons and exhibit a reduced amount of intermediate filaments and an increased cell saturation density. Exp Cell Res 239(2):332-343. https://doi.org/10.1006/excr.1997.3922

45. Puschmann TB, Zanden C, De Pablo Y, Kirchhoff F, Pekna M, Liu J, Pekny M (2013) Bioactive 3D cell culture system minimizes 
cellular stress and maintains the in vivo-like morphological complexity of astroglial cells. Glia 61(3):432-440. https://doi.org/10. 1002/glia.22446

46. Lepekhin EA, Eliasson C, Berthold CH, Berezin V, Bock E, Pekny M (2001) Intermediate filaments regulate astrocyte motility. J Neurochem 79(3):617-625

47. Larsson A, Wilhelmsson U, Pekna M, Pekny M (2004) Increased cell proliferation and neurogenesis in the hippocampal dentate gyrus of old $\mathrm{GFAP}^{(--)} \mathrm{Vim}^{(--)}$mice. Neurochem Res 29(11):20692073

48. Puschmann TB, de Pablo Y, Zanden C, Liu J, Pekny M (2014) A novel method for three-dimensional culture of central nervous system neurons. Tissue Eng Part C-Methods 20(6):485-492. https:// doi.org/10.1089/ten.tec.2013.0445

49. Puschmann TB, Zanden C, Lebkuechner I, Philippot C, de Pablo Y, Liu J, Pekny M (2014) HB-EGF affects astrocyte morphology, proliferation, differentiation, and the expression of intermediate filament proteins. J Neurochem 128(6):878-889. https://doi.org/ 10.1111/jnc. 12519

50. Andreasson KI, Bachstetter AD, Colonna M, Ginhoux F, Holmes C, Lamb B, Landreth G, Lee DC et al (2016) Targeting innate immunity for neurodegenerative disorders of the central nervous system. J Neurochem 138(5):653-693. https://doi.org/10.1111/jnc. 13667

51. Chang L, Goldman RD (2004) Intermediate filaments mediate cytoskeletal crosstalk. Nat Rev Mol Cell Biol 5(8):601-613. https:// doi.org/10.1038/nrm1438

52. Boyer S, Maunoury R, Gomes D, Denechaud B, Hill AM, Dupouey $P$ (1990) Expression of glial fibrillary acidic protein and vimentin in mouse lens epithelial-cells during development Invivo and during proliferation and differentiation in vitro-comparison with the developmental appearance of GFAP in the mouse central-nervoussystem. J Neurosci Res 27(1):55-64. https://doi.org/10.1002/jnr. 490270109 